\title{
Assessing Campus Sustainability: An ISO 14001 Approach
}

\author{
Nadia A. Setyorini ${ }^{1}$, M. Mujiya Ulkhaq ${ }^{1}$, Dyah R. Rasyida ${ }^{1}$, Priska R. Setiowati ${ }^{1}$, and Reza Trianto $^{1}$
}

\begin{abstract}
Over the past decade, there has been a rising of international attention in the role of higher education in promoting sustainability. As consequences, several colleges and universities have established projects, programs, and initiatives to integrate sustainability into their systems. Universities could implement ISO 14001 that is recognized as a guide for an organization which aim to implement an environmental management system to pursue the sustainability. ISO 14001 checklist is designed for organizations to self-assess in determining how closely existing management practices and procedures match to the elements of ISO 14001. The objective of this research is to assess the sustainability practice of Diponegoro University using ISO 14001 checklist. It consists of 31 questions that are classified into five main principles: management review, checking and corrective actions, implementation and control, planning, as well as environmental policy. A case study is conducted through direct observation, data and document collections, along with in depth interview with some experts who have rich experiences in the field of environmental management system. The result indicates that Diponegoro University has employed the requirements entailed in ISO 14001 standards due to its high score. It is recommended to conduct similar research which covers not only environmental aspect, but also economic, social, together with sustainability research and teaching.
\end{abstract}

Keywords_campus sustainability, EMS, ISO 14001, universities.

\section{INTRODUCTION}

Sustainable development is broadly noticed as development that improves the standard of living and quality of life, while at the same time keeping and enhancing the environment and honouring local culture and history. It can be defined as any construction that can be preserved and wellkept over a long period of time without causing any harm to the environment and with the protection for the future generations. In today's highly competitive business environment, efforts are being made all over the world for achieving the sustainability.

Universities are contended to be in a unique position to address this challenge. Although their global mission is education and not social action, but they do give an education to the citizenry with interdisciplinary knowledge that are capable of having large impacts on the environment as well as some influences on local and global communities [1]. There has been a significant growth of widespread understanding and implementation of sustainability principles in the universities [2], [3]. As a consequence, there is an increasing number of

\footnotetext{
${ }^{1}$ Department of Industrial Engineering, Diponegoro University, Semarang, Indonesia
}

universities, as higher education institutions that have been engaged in incorporating and institutionalizing sustainability into their curricula, research, outreach, operations, as well as assessment and reporting [4], [5].

The journey began in the early 1970s when the Stockholm Declaration on the Human Environment is organized. It is recognized as the first reference about sustainability in higher education. Since then, there are plenty events, conferences, and declarations related to the role of higher education in nurturing a sustainable future, from Belgrade Charter in 1975, Earth Summit in Rio de Janeiro in 1992, until Tokyo Declaration in 2009 (for a list of declaration on higher education and sustainable development, see [6]). As results of those aforementioned declarations, several colleges and universities have embarked on projects and initiatives to incorporate sustainability into their systems. These initiatives are based on the university environmental goals along with university management's concept of sustainability since the concept presents diverging interpretations according to the actors that are implied [7]. For some universities, a sustainable university is having a master plan, environmental plan, guidelines, or statement [8]; while some consider that they have met the challenge of sustainability by signing of national or international declarations [9]; others create individual institutional policies as a means of achieving campus sustainability.

One practice which is widely engaged by universities in achieving sustainability is the ISO 14001 standards [10], which has been implemented by a large number of universities in the world, see for example [11]-[13]. Although it is wellknown as a certification for organization in term of environmental management process, the ISO 14001 may be very useful to be implemented in higher education as an effort for pursuing sustainability. This ISO 14001 contains a checklist as an assessing tools for evaluating the adherence between the standard and what have been done by an organization to achieve sustainability. This research attempted to assess the sustainability practice of Diponegoro University, which is located in Semarang, Indonesia, using the ISO 14001 checklist. This research could contribute in a sustainability reporting in higher education [14].

\section{RESEARCH DESIGN}

The ISO 14001 standards are the main international references for an organization that aim to implement an environmental management system (EMS) and obtain an environmental certification processes. It provides guidelines for organizations to design and implement an EMS that 
identifies the organization's environmental policy, the environmental aspects of its operations, legal and other requirements, a set of clearly defined objectives and targets for environmental improvement, as well as a set of environmental management programs [15].

The first version of ISO 14001 which is based on the iterative plan-do-check-act (PDCA) logic of quality management systems (see Fig. 1), was issued by the ISO in 1996 [16]. A second edition of ISO 14001 was published in 2004, updating the standard. Later it has become the most popular and frequently used international standard for implementing an EMS, an infrastructure to manage the organization's interaction with the environment [17]. Since its launch in 1996, ISO 14001 certification has experienced intensive growth on the international stage: in 2014, at least 324,148 ISO 14001:2004 certificates had been issued in 171 countries, a growth of $7 \%$. Growth was driven by East Asia and North America, boasting $10 \%$ and $14 \%$ respectively. The latter was supported, in Canada, Mexico and the USA, by new certification bodies entering the survey, while existing contributors in the USA also reported significantly more certificates. Australia experienced exponential growth with a major certification body reporting more certificates than usual, while the increase recorded in the Czech Republic and Turkey mainly reflects the inclusion of previously unreported certificates. Overall, however, China enjoys the highest growth in absolute numbers with a 13,023 increase in certificates issued [18].

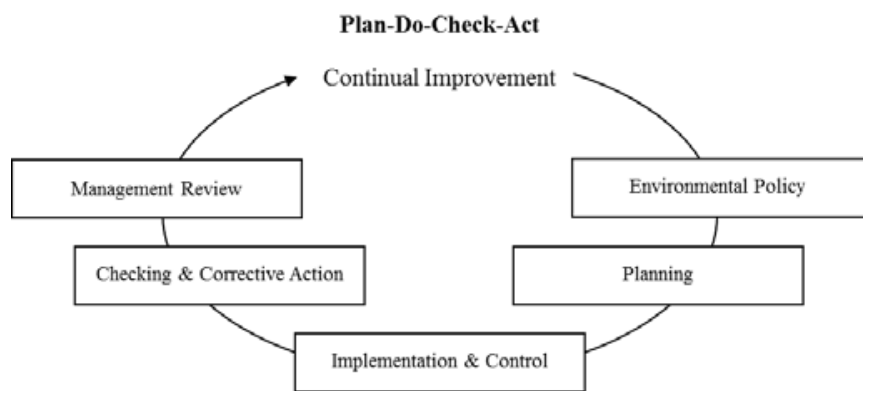

Fig. 1: Plan-Do-Check-Action Process in ISO 14001

ISO 14001 contains five main principles (elements) which is depicted in Fig. 1. The first main element is management review, which is periodic management review of the overall EMS to ensure its suitability, adequacy, and effectiveness in light of changing circumstances. The second includes procedures for regular monitoring and measurement of key characteristics of the operations and activities, procedures for dealing with situations of non-conformity, specific record maintenance procedures, and procedures for auditing the performance of the EMS. The third refers to EMS that should implement and operate the definition, documentation and communication of roles and responsibilities, provision of appropriate training, assurance of adequate internal and external communication, written management system documentation as well as appropriate document control procedures, documented procedures for operational controls, and documented and communicated emergency response procedures. The fourth covers the identification of the environmental aspects of the organization's activities, identification and access to legal requirements, establishment and documentation of objectives and targets consistent with the policy, and establishment of a program for achieving targets and objectives (including the designation of responsible individuals, necessary means and timeframes). The last comprises the establishing of an appropriate environmental policy that is documented and communicated to employee and made available to the public, and which includes a commitment to continual improvement and pollution prevention, regulatory compliance, and a framework for setting objects.

These five elements are supported by sub-elements that make up the framework. It has a total of 31 questions in five different sections, corresponding to five elements aforesaid. The score " 0 " is given when the reality does not comply at all with the requirement; the score " 1 " is given when the requirement is more or less fulfilled, but where there is still room for improvement; and finally when the situation in which the requirement appears to be completely fulfilled and a score “2” applies. In order to assess the sustainability practices of Diponegoro University, data and document collection has been done by compiling the information through university website and other documents related to the implementation of sustainability practices [19]. An interview has been conducted with the university's stakeholders, professors, lecturers, and students of the university.

\section{RESULT \& DISCUSSION}

The result, which is the final score of Diponegoro University assessment using ISO 14001 checklist is depicted in Table 1 . The university has score 12 points on the commitment and policy principle. The result, which is the final score of Diponegoro University assessment using ISO 14001 checklist is depicted in Table 1 . The university has score 12 points on the commitment and policy principle. It means that top management of the university has launched, established, instituted, and documented an environmental policy that meets most of the criteria depicted in the ISO 14001 checklist. This policy takes into account most of the environmental aspects and is well communicated, both inside and outside of the university. When the score ranges from 0 to 5 , the organization either has no environmental policy or its policy lacks of commitment; when the score ranges from 6 to 10 , there is environmental policy that meets many of the requirements established under the standard; the perfect score, 11 to 14, means that top management has established and documented an environmental policy that meets most of the criteria.

The second principle, planning, the total score is 7 points. It means that the required procedures has identify how its activities, products, and services impact the environment, and has kept up to date on changing regulations. All of the changing regulations has been well distributed to all of the faculties and has been implemented. Measurable targets and objectives have been set for most appropriate levels of the university; an action program exists to ensure their attainment. However, the application of the rules that have been distributed are still considering the condition of each of the existing faculties. If possible, it will be implemented and if 
not, then it will be given terms and requirements agreed between the university and the faculty's top management. When the score ranges from 0 to 3 , the organization's environmental management program is insufficient; when the score ranges from 3 to 6 , there is some objectives and targets, but much progress is still required; when the

TABLE I:

RESULTS OF AsSESSMENT USING ISO 14001 CHECKLIST IN DIPONEGORO UNIVERSITY

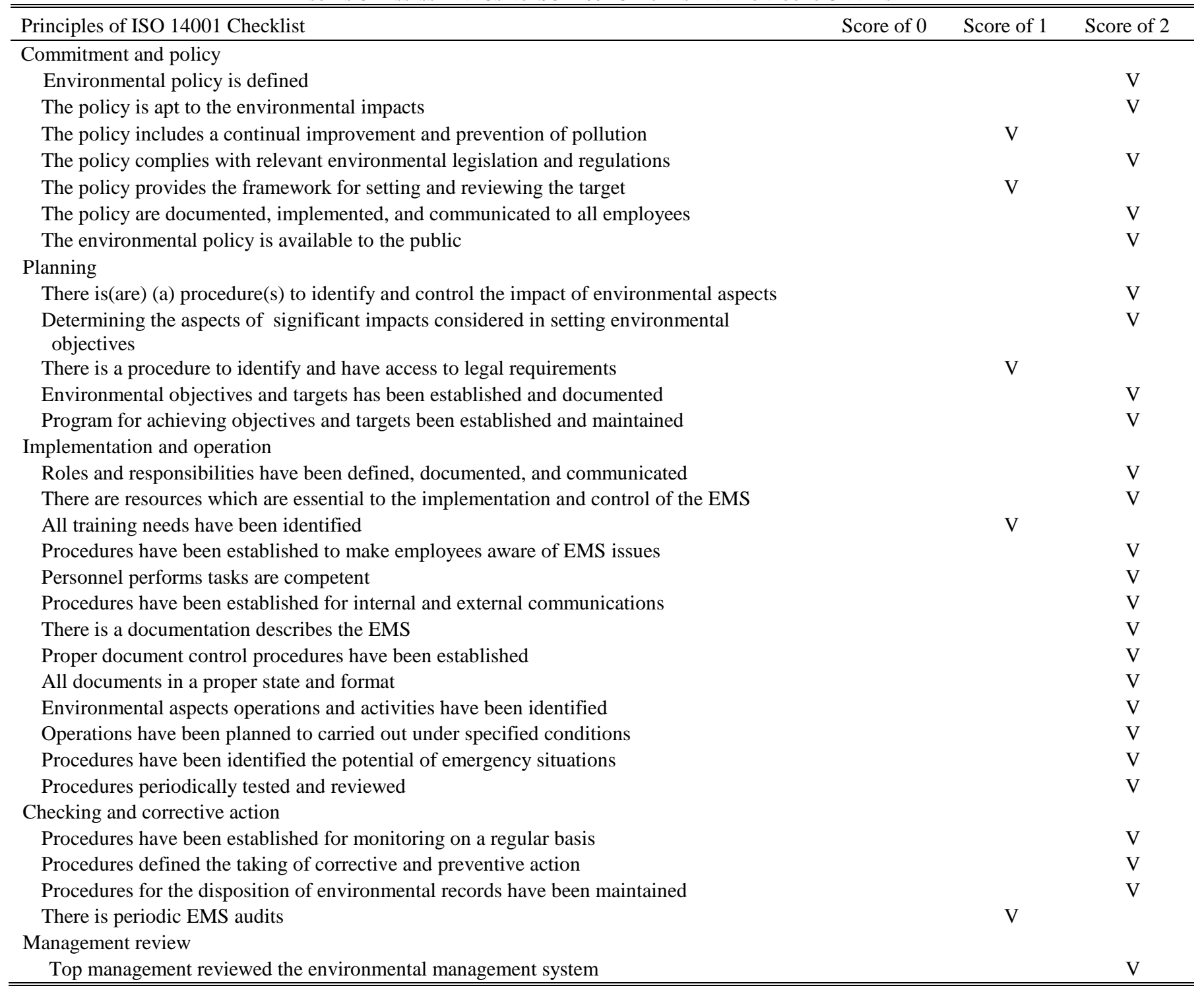

score ranges between 6 to 10, measurable targets and objectives have been set for most levels of the organization.

For the implementation and operation principle, the total score is 23 points. It means that Diponegoro University has assigned the areas of responsibility and has allocated the resources well. Operating and other procedures have been developed, documented and communicated. Most of the personnel are trained in their use and in complying with their environmental responsibilities. This university controls all documents exist to ensure that systems are kept up to date. When the score ranges from 1 to 8 , the procedures do not fully take into account all environmental aspects of the organization; score 9 to 18 means that many procedures exist, but they might not include emergency situations; while score 19 to 26 means that operating and other procedures have been developed, documented, and communicated.
The fourth principle, checking and corrective action, the total score is 9 points. It means that Diponegoro University has implemented the majority of procedures and programs described in the standard to effectively and regularly monitor and measure the applicable characteristics of operations and activities, as well as to detect and correct areas of nonconformity. EMS adequate procedures exist for management of most appropriate records, and a regular EMS audit program has been established. When the score ranges from 1 to 3 , it means that few procedures have been implemented for checking the performance of the EMS; score 4 to 7 means that there are measurement and evaluation procedures, but much improvement still needed; while score 8 to 10 means that the organization has implemented the majority of procedures. For the last principle, management review, the total score is 2. It 
means that Diponegoro University periodically review the basic assumptions upon which its EMS is based.

\section{CONCLUSION AND FUTURE RESEARCH DIRECTION}

The research has demonstrated the assessment of campus sustainability using ISO 14001 checklist. A case study has conducted at the Diponegoro University to assess its performance in pursuing the sustainability. The result shows that overall Diponegoro University scored high in any principle. However, it is not necessarily a sign that the requirement is essentially met, if the core key criteria in that section are not met. Since the university scored at least 1 or 2 in each question, it should give the university the confidence that its management approaches are compatible with the EMS as described in ISO 14001.

However, although ISO 14001 could make a momentous contribution in promoting campus sustainability, but the standard is without flaw. It is lack of social dimension [20] and that it focuses predominantly on the environmental dimensions, giving little or no consideration to economic or social issues [21]. Thus, it recommends to conduct similar research using assessment tools which covers environmental aspect, economic, social, or sustainability research and teaching [22].

\section{ACKNOWLEDGMENT}

Authors would like to thank to Prof. Sudharto P. Hadi, former Rector of Diponegoro University for his valuable support for this research.

\section{REFERENCES}

[1] C. Uhl and A. Anderson, "Green destiny: universities leading the way to a sustainable future," BioScience, vol. 51, no. 1, pp. 36-42, 2001. http://dx.doi.org/10.1641/00063568(2001)051[0036:GDULTW]2.0.CO;2

[2] W. L. Filho, Sustainability at Universities: Opportunities, Challenges and Trends, Frankfurt: Peter Lang Scientific Publishers, 2010.

[3] W. L. Filho, "Putting Concepts of Sustainable Development into Practice at Higher Education Institutions: Experiences from the SKINT Project," in Sustainable Development at Universities: New Horizons, W. L. Filho, Ed. Frankfurt: Peter Lang Scientific Publishers, 2012.

[4] W. Calder and R. M. Clugston, "International efforts to promote higher education for sustainable development," Planning for Higher Education, vol. 31, no. 3, pp. 30-44, 2003.

[5] A. D. Cortese, "The critical role of higher education in creating a sustainable future”, Planning for Higher Education, vol. 31, no. 3, pp. 15-22, 2003.

[6] M. M. Ulkhaq, P. I. Prayogo, M. Firmansyah and D. Agustina, "Assessing campus sustainability: a report from Diponegoro University, Indonesia," International Journal of Information and Education Technology, vol. 6, no. 8, pp. 616-621, 2016. http://dx.doi.org/10.7763/IJIET.2016.V6.761

[7] N. Lourdel, N. Gondran, V. Laforest, and C. Brodhag, "Introduction of sustainable development in engineer's curricula: Problematic and evaluation methods," International Journal of Sustainability in Higher Education, vol. 6, no. 3, pp. 254-264, 2005. http://dx.doi.org/10.1108/14676370510607223

[8] L. Velazquez, N. Munguia, A. Platt, and J. Taddei, "Sustainable university: What can be the matter?” Journal of Cleaner Production, vol. 14, no. 9-11, pp. 810-819, 2006. http://dx.doi.org/10.1016/j.jclepro.2005.12.008

[9] T. S. A. Wright, "Definitions and frameworks for environmental sustainability in higher education," Higher Education Policy, vol. 15, no. 2, pp. 105-120, 2002.

http://dx.doi.org/10.1016/S0952-8733(02)00002-8
[10] ISO 14001:2004, International Organization for Standardization, 2004.

[11] R. M. Fisher, "Applying ISO 14001 as a business tool for campus sustainability: A case study from New Zealand,” International Journal of Sustainability in Higher Education, vol. 4, no. 2, pp. 138-150, 2003. http://dx.doi.org/10.1108/14676370310467159

[12] T. J. Price, "Preaching what we practice: Experiences from implementing ISO 14001 at the University of Glamorgan," International Journal of Sustainability in Higher Education, vol. 6, no. 2, pp. 161-178, 2005. http://dx.doi.org/10.1108/14676370510589873

[13] K. Sammalisto and T. Brorson, "Training and communication in the implementation of environmental management systems (ISO 14001): A case study at the University of Gävle, Sweden,” Journal of Cleaner Production, vol. 16, no. 3, pp. 299-309, 2008. http://dx.doi.org/10.1016/j.jclepro.2006.07.029

[14] K. Ceulemans, I. Molderez, and L. Van Liedekerke, "Sustainability reporting in higher education: a comprehensive review of the recent literature and paths for further research," Journal of Cleaner Production, vol. 106, pp. 127-143, 2015. http://dx.doi.org/10.1016/j.jclepro.2014.09.052

[15] S. L. Jackson, The ISO 14001 Implementation Guide: Creating an Integrated Management System, New York: Wiley, 1997.

[16] D. Morrow and D. Rondinelli, “Adopting corporate environmental management systems: Motivations and results of ISO 14001 and EMAS certification,” European Management Journal, vol. 20, no. 2, pp. 159171, 2002. http://dx.doi.org/10.1016/S0263-2373(02)00026-9

[17] J. González-Benito, G. Lannelongue and D. Queriga, "Stakeholders and environmental management systems: A synergistic influence on environmental imbalance," Journal of Cleaner Production, vol. 19, no. 4, pp. 1622-1630, 2011. http://dx.doi.org/10.1016/j.jclepro.2011.05.013

[18] ISO. (2015). The ISO Survey of Management System Standard Certifications - $2014 . \quad$ [Online]. Available: www.iso.org/iso/iso_survey_executive-summary.pdf.

[19] R. K. Yin, Case Study Research: Design and Methods (Applied Social Research Methods), 5th ed., London: Sage Publication, Inc., 2013.

[20] U. Steger, "Environmental management systems: Empirical evidence and further perspectives, European Management Journal, vol. 18, no. 1, pp. 23-27, 2000. http://dx.doi.org/10.1016/S0263-2373(99)00066-3

[21] R. Lozano, "A tool for a graphical assessment of sustainability in universities (GASU)," Journal of Cleaner Production, vol. 14, no. 9, pp. 963-972, 2006. http://dx.doi.org/10.1016/j.jclepro.2005.11.041

[22] H. M. Alshuwaikat and I. Abubakar, "An integrated approach to achieving campus sustainability: assessment of the current campus environmental management practices," Journal of Cleaner Production, vol. 16, no. 16, pp. 1777-1785, 2008. .

http://dx.doi.org/10.1016/j.jclepro.2007.12.002 